\title{
Myasthenia Class I
}

National Cancer Institute

\section{Source}

National Cancer Institute. Myasthenia Class I. NCI Thesaurus. Code C112014.

Any ocular weakness. All other muscles strength is normal. 